\title{
Vzroki in vplivi decembrskega vetroloma (2017) na nadaljnji razvoj jelovo bukovih sestojev v Sloveniji
}

Zaključna delavnica

CRP V4-1820
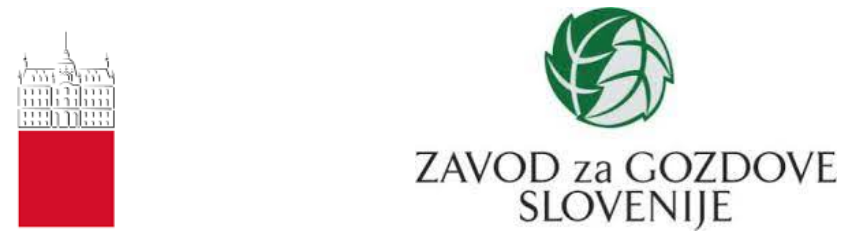
Založnik: Gozdarski inštitut Slovenije, založba Silva Slovenica, Ljubljana 2021 Naslov: Vzroki in vplivi decembrskega vetroloma (2017) na nadaljnji razvoj jelovo bukovih sestojev v Sloveniji - zbornik zaključne delavnice Urednik: Matjaž Čater Tehnični urednik: Peter Železnik Izdaja: elektronska izdaja Elektronski izvod: http://dx.doi.org/10.20315/SilvaSlovenica.0017 


\section{Kazalo vsebine}

Cilji in raziskovalne lokacije projekta

Talne lastnosti prizadetih in neprizadetih območij po vetrolomu ter značilnost koreninskih sistemov jelk 5

Model potencialne ogroženosti jelovo bukovih gozdov glede na možnost nastanka podobnih ekstremnih vremenskih dogodkov 6 Primerjava uspešnosti in učinkovitosti obnove prizadetih in neprizadetih površin

Ocena učinkovitosti odvračal na objedenost mladja ............................... 8

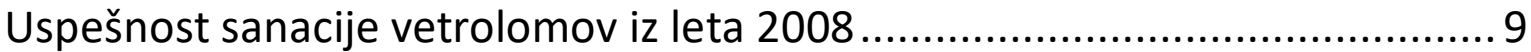

Gozdnogojitvene usmeritve za obnovo gozdov po naravnih ujmah. 10 Kakovostna in dimenzijska strukture gozdno-lesnih sortimentov glede na stopnjo poškodovanosti sestojev 


\section{Cilji in raziskovalne lokacije projekta}

\section{Cilji:}

1 - Določiti lastnosti tal prizadetih in neprizadetih območij in opredeliti značilnost koreninskih sistemov najbolj prizadetih drevesnih vrst - jelke (DS1);

2 - Izdelati model potencialne ogroženosti širšega območja jelovo-bukovih gozdov glede na možnost podobnih ekstremnih vremenskih pojavov (DS 2);

3 - Primerjati uspešnost in učinkovitost obnove prizadetih in neprizadetih površin (DS 3);

4 - Primerjati uspešnost sanacije površin zadnjega vetroloma (2017) z učinkovitostjo sanacije starejših poškodovanih površin in izdelali napotke za optimalno obnovo sedanjih prizadetih površin (DS 4).

5 - Analizirati strukturo gozdno-lesnih sortimentov in izdelati oceno ekonomske izgube glede na strukturo gozdnih sestojev (DS 5).

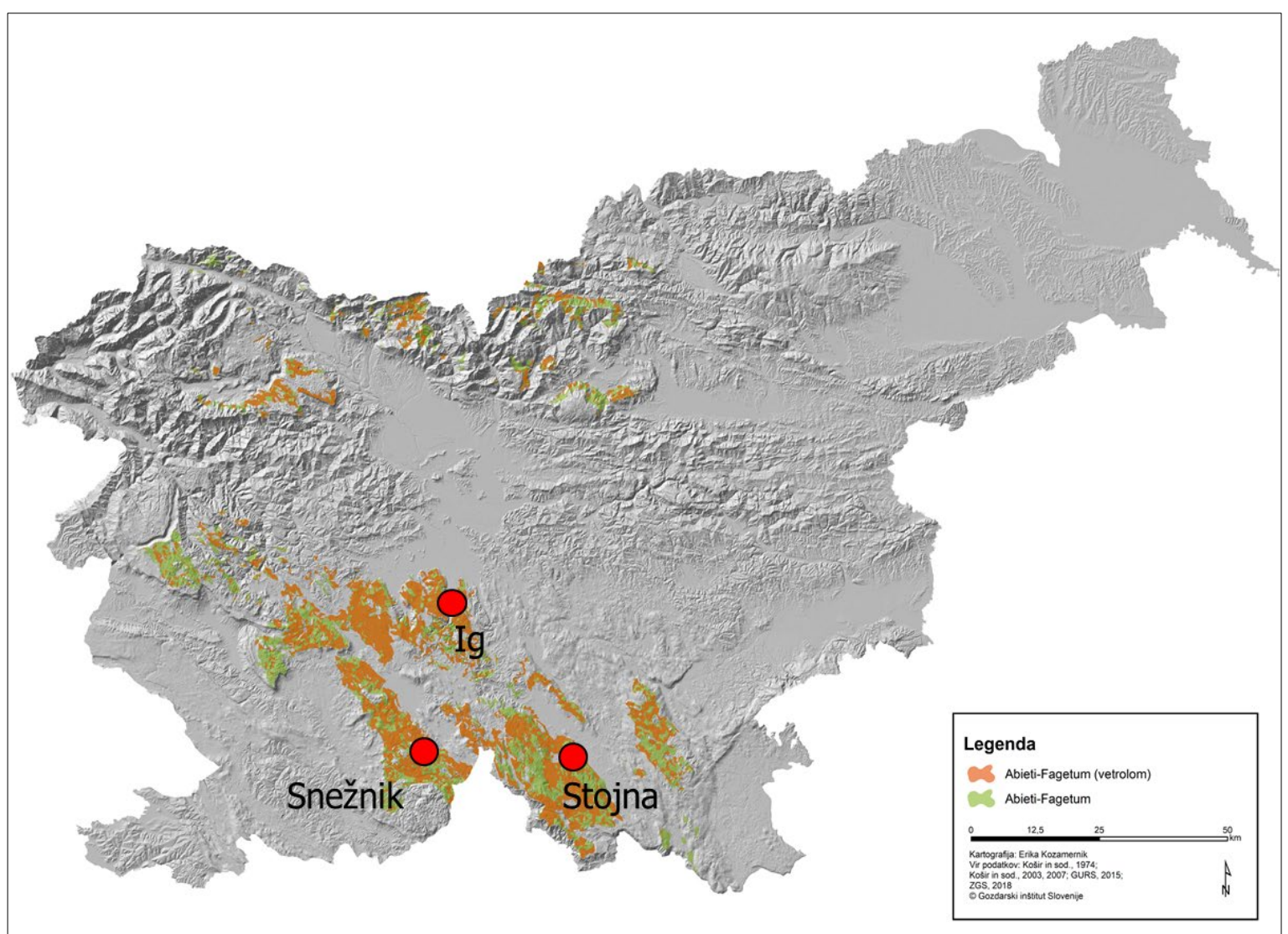

Slika 1: Raziskovalne lokacije 


\title{
Talne lastnosti prizadetih in neprizadetih območij po vetrolomu ter značilnost koreninskih sistemov jelk
}

\author{
A. Marinšek, P. Železnik, M. Ferlan, L. Kutnar, D. Žlindra
}

Raziskali smo mikrorastiščne razmere in značilnosti 30 jelk (15 podrtih (P) in 15 stoječih (S)) na 3 lokacijah rastišča združbe Omphalodo-Fagetum.

Orkanski veter decembra 2017 jelk ni prelamljal, temveč izruval s koreninskim sistemom vred.

Geološka podlaga je povsod enaka: apnenec in dolomit.

Zdravstveno stanje vseh P in S dreves je bilo večinoma odlično.

Zdravstveno stanje koreninskih sistemov vseh podrtih in stoječih dreves je bilo večinoma odlično.

Jelke na plitvih tleh so dovzetnejše za izruvanje (trend manjšega deleža podrtih jelk na globljih rjavih pokarbonatnih tleh je samo nakazan).

Fizikalne in kemijske lastnostih tal na mestih izruvanih in stoječih jelk se statistično niso razlikovale. Delež gline $v$ tleh je bil na vseh mikrolokacijah podoben, statistično nerazličen.

$\mathrm{H}: \mathrm{d}$ razmerja podrtih dreves nismo mogli izračunati, ker je bila sanacija vetrolomnih površin izvedena pred našimi raziskavami: dimenzijsko razmerje podrtih dreves (jelk) je neznano.

$\mathrm{Na}$ izruvanje jelk $v$ veliki meri ne vpliva število najdebelejših korenin, ki izraščajo iz koreničnika, temveč njihova postavitev glede na smer najmočnejših vetrov (čim manjši kot).

Rast najdebelejših korenin iz koreničnika v smeri orkanskega vetra nudi dobro oporo jelki (sidro).

Pomembna prisotnost debelih korenin na privetrni strani.

Skalovit kraški teren z menjavanjem globin/tipov tal ter žepastimi tlemi onemogoča razvoj simetrične (iz)rasti glavnih, najdebelejših korenin, ki so pogoj za mehanično stabilnost dreves $v$ vseh smereh.

Na koreninski sistem z gojitvenimi ukrepi težko vplivamo, vplivamo lahko na h:d razmerje. Manjše razmerje omogoča večjo stabilnost dreves pri pojavu orkanskega vetra. 


\title{
Model potencialne ogroženosti jelovo bukovih gozdov glede na možnost nastanka podobnih ekstremnih vremenskih dogodkov
}

\author{
M. Ferlan, A. Kobler, E. Kozamernik
}

Med leti 1995 in 2017 so bili vetrolomni dogodki evidentirani v 46.3\% odsekih, med leti 1995 in 2018 pa v 49.8\% odsekih. Samo v enem letu (dveh dogodkih) je prišlo do 3.5\% povečanja. Primerjavo poškodb v obdobju 1995-2017 in letu 2018 prikazuje naslednja preglednica:

Preglednica 1: Poškodbe v obdobju 1995-2017 in 2018

\begin{tabular}{|l|r|r|}
\hline \multicolumn{1}{|c|}{ OBDOBJE } & \multicolumn{1}{|c|}{$\mathbf{1 9 9 5 - 2 0 1 7}$} & \multicolumn{1}{c|}{$\mathbf{2 0 1 8}$} \\
\hline Delež v vetrolomu poškodovanih dreves glede na vsa posekana drevesa & $2.6 \%$ & $34.4 \%$ \\
\hline Delež v vetrolomu poškodovanih $\left(\mathrm{m}^{3}\right)$ glede na celoten posek $\left(\mathrm{m}^{3}\right)$ & $3.7 \%$ & $45.3 \%$ \\
\hline Povprečno posekano drevo zaradi vetroloma $\left(\mathrm{m}^{3}\right)$ & $1.10 \mathrm{~m}^{3}$ & $1.49 \mathrm{~m}^{3}$ \\
\hline Povprečno posekano drevo zaradi drugih vzrokov $\left(\mathrm{m}^{3}\right)$ & $0.78 \mathrm{~m}^{3}$ & $1.13 \mathrm{~m}^{3}$ \\
\hline
\end{tabular}

Analizali smo vremensko dogajanje in mikrorastiščne talne razmere pred vetrolomom (matična podlaga, ekspozicija, nadmorska višina, vrsta/struktura sestojev).

Vključeni so bili vsi pretekli vetrolomni dogodki v odsekih (baza ZGS, timber' ) zabeleženih od leta 1995 do 2019 in meteorološki podatki od leta 2000 do 2019. Vetrolome in vremensko dogajanje smo časovno uskladili. Priprava modela potencialne ogroženosti širšega območja jelovo-bukovih gozdov je bila izdelana na možnost podobnih ekstremnih vremenskih pojavov.

Predhodna namočenost tal $v$ kombinaciji $z$ močnejšimi sunki vetra povzročij izruvanje drevja; odločilen je veter, ki ne piha iz stalne smeri.

Verjetnost izruvanja drevja ob naslednjem dogodku se stopnjuje s številom zaporednih dogodkov z močnim in viharnim vetrom. Tla in matična podlaga vplivata na verjetnost izruvanja. Trend je nakazan, vendar statistično ni značilen. 


\title{
Primerjava uspešnosti in učinkovitosti obnove prizadetih in neprizadetih površin
}

\author{
M. Čater, K. Flajšman, A. Alagić
}

Odziv prevladujočih drevesnih vrst v mladju smo ocenjevali na vseh treh lokacijah (Snežnik, Stojna, Ig) v treh svetlobnih kategorijah: pod zastorom, na gozdnem robu in na odprtem - na hitro presevetljenih površinah kot posledica vetroloma in površinah, kjer se je mladje postopno prilagodilo na svetlobne razmere zaradi načina gospodarjenja.

$\mathrm{V}$ kontroliranih okoljskih pogojih $\left(\mathrm{T}\right.$, vlaga, $\left.\mathrm{CO}_{2}\right)$ smo $\mathrm{v}$ optimalnih okoljskih razmerah merili učinkovitost mladja bukve, jelke, smreke in g.javorja.

Pri bukvi se je učinkovitost vsako leto povečevala $v$ vsaki od svetlobnih kategorij, podobno in posebno izrazito prvo leto po ujmi pri g. javorju. Učinkovitost jelke se je zmanjševala $s$ povečevanjem svetlobe in z vsakim nadaljnim letom po ujmi. Odzivi smreke so bili indiferentni.

Mikrolokacije z izenačeno tekmovalno močjo med proučevanimi drevesnimi vrstami so se z leti pomikale v smer popolne zastrtosti, predvsem zaradi zmanjševanja učinkovitosti jelke.

Številčnost osebkov se je na vsaki lokaciji zmanjševala, najizraziteje pri jelki.

Vzporejanje odziva med žledom in vetrolomom na prizadetih površinah je bilo med vrstami podobno, vendar se je učinkovitost po žledu povečevala počasneje, kot po vetrolomu. Žled je prizadel površine z mladjem močneje, kot vetrolom.

Zmanjševanje števila osebkov je posledica stresa zaradi hitre presvetlitve, objedanja in naravne selekcije; zmotno je pripisovanje upada številčnosti le enemu dejavniku.

Opazno je povečevanje učinkovitosti listavcev in počasnejša odzivnost iglavcev. Kljub manjšemu nazadovanju jelke po vetrolomu $v$ primerjavi z žledom je bil pomik izenačene tekmovalne moči med proučevanimi vrstami po vetrolomu v smeri popolnega zastora podoben. 


\title{
Ocena učinkovitosti odvračal na objedenost mladja
}

\author{
A. Alagić, M. Ferlan, K. Flajšman, M. Čater
}

Na vseh lokacijah v mladju prevladujejo plemeniti listavci, predvsem gorski javor. Na Igu dosegajo skoraj enak delež drugi trdi listavci, predvsem mali jesen.

Na Igu je v primerjavi z drugimi lokacijami najmanj jelke, v Kočevju pa skoraj ni smreke.

Med obema popisoma (2019 in 2021) na Igu nismo opazili bistvenih razlik, razen večje številčnosti bukve. Na Snežniku in v Kočevju smo zaznali močno zmanjševanje deleža jelke ter večanje deleža plemenitih listavcev in bukve.

V višino na vseh lokacijah uspešno prerašča le bukev, na Snežniku še v manjšem deležu plemeniti in drugi trdi listavci.

Kemična odvračala so relativno poceni in njihova uporaba je enostavna. Potrebno je redno obnavljanje, posebno pozimi po padavinah. Njihova glavna pomanjkljivost je slabše delovanje pod $10^{\circ} \mathrm{C}$; ker pritegnejo medvede, jih le ti lahko poškodujejo.

Zvočna odvračala so enostavna za namestitev. Glavno pomanjkljivost lahko predstavlja slab signal, zato ni povratne informacije ali odvračalo deluje ali ne; priporočljivo je redno pregledovanje delovanja (poškodbe zaradi vandalizma).

Poškodovanost se je na vseh ploskvah povečala, najmanjše povečanje poškodb smo opazili na ploskvah s kemičnimi odvračali.

Največjo poškodovanost mladja smo potrdili v obeh popisih na Igu, na Snežniku pa smo opazili največje povečanje poškodb.

Analiza vedenjskih odzivov pri jelenjadi in srnjadi ni pokazala bistvenih razlik med ploskvami. 


\section{Uspešnost sanacije vetrolomov iz leta 2008}

G. Fidej, D. Roženbergar, J. Diaci, M. Cerioni, A. T. Nagel

Naravna obnova ima velik potencial na večini obravnavanih rastišč.

Skupne gostote (vključno s sadikami) so bile 11 let po ujmi večje na površinah naravne obnove.

Z obžetvijo odstranjujemo samoniklo naravno mladje - izobraževanje delavcev/lastnikov o drevesnih vrstah.

Na površinah naravne obnove je več sencozdržnih (komercialno zanimivih) vrst kot na sajenih. Alternativa saditvi je nega naravnega mladja (označevanje s količki in obžetev)

Saditev je smiselna v skrajnostnih razmerah: višje NMV, prisojne lege, brez pomladka, večje odprtine brez semenjakov, obstoječa bujna pritalna vegetacija 


\section{Gozdnogojitvene usmeritve za obnovo gozdov po naravnih ujmah}

J. Diaci, G. Fidej, D. Roženbergar, M. Cerioni, A. T. Nagel, T. Adamič

Ujm ni mogoče preprečiti, lahko izboljšamo odpornost sestojev in njihovo sposobnost okrevanja z rednim gospodarjenjem, mešanimi raznomernimi gozdovi, uvajanjem novih negovalnih modelov s poudarkom na kolektivni stabilnosti in aktivnim pospeševanjem polnilne plasti v bolj enomernih strukturah.

Izpeljava sanitarne sečnje je umestna le, kadar je ogroženo zdravje, če je renta pozitivna in ni potrebno zagotoviti varovalnih funkcij. Pomembna je jakost sanitarne sečnje in puščanje ostankov kljub poškodovanosti sestoja.

Raziskave kažejo na dobra preživetveno sposobnost listavcev kljub močnim poškodbam krošnje, trg lesa je po ujmi zasičen in puščanje pomeni tudi zamik plasiranja na trg; četudi gre za drva, so ta drevesa vir semen.

Presoja rastišča, sestoja in pomladka: $v$ primeru nizkih gostot, več negativnih dejavnikov za pomlajevanje ali poudarjene varovalne/zaščitne funkcija se odločamo za umetno obnovo.

Izboljševanje naravne obnove: ohranjanje gozdnega roba in poškodovanih dreves, izpeljava analizo pomladka in mladja, označevanje in obžetev; zaradi velikih površin obnove določiti prioritete in uvajati situacijsko nego

Umetna obnova:

Analize kažejo na zadovoljiv uspeh saditve smreke, ki ni nujno najprimernejša vrsta; težave pri listavcih - kakovost sadik in pomanjkanje kontrole pri vzgoji sadik listavcev, velike možnosti kasnejše naravne nasemenitve.

Potencial uporabe puljenk (upoštevati priporočila za pridobivanje in saditev).

Setev je zanimiva alternativa, nujna je priprava tal in nekajletna obžetev.

Izboljšave umetne obnove dosežemo s saditvijo/setvijo na izbrana mesta, saditvijo skupin, kombiniranje, uvajanjem vrst za boljšo odpornost na podnebne spremembe.

Težave s prekomernim objedanjem mladja: divjad lahko z objedanjem zmanjšuje gostote in višinsko rast mladja ter spreminja zmes $v$ korist smreke, zato je prilagajanje sestojev na podnebne spremembe oteženo. Predlagamo postavitev kontrolnih ograj in spremljanje objedenosti mladja na najbolj izpostavljenih predelih, zniževanje gostot divjadi, preverjanje učinkovitosti večjega števila manjših ograd s sajenimi listavci ali jelko.

Nega: obžetev, kasneje usmerjena, zmerna nega s pogostimi ukrepi, vendar majhnim številom izbrancev $v$ smislu situacijske nege. Cilji so lahko prilagojeni tudi z nadaljnjim zmanjševanjem števila izbrancev - do 50, izobraževanjem delavcev (poznavanje drevesnih vrst) itd.

Nepristransko kvantificiranje učinkov sanacije je mogoče z zastavitvijo poskusov v naravi (močan vpliv kakovosti sadik pri umetni obnovi, uvedba kontrole od pridelave do saditve). 


\title{
Kakovostna in dimenzijska strukture gozdno-lesnih sortimentov glede na stopnjo poškodovanosti sestojev
}

\author{
J. Jevšenak, T. Levanič
}

Ekonomske škode zaradi vetroloma smo ocenjevali po metodi, ki jo je predstavil Žgajnar (1990).

Skupno ocenjene količinske izgube znašajo 205855 m3 oziroma 5,6 \% manj, kot če bi bila drevesa posekana v redni sečnji.

Če izgubljeno biomaso pretvorimo v ekonomske izgube, ocenjujemo neposredni izpad dohodka na $16,1 \mathrm{M} €$.

Upoštevati je potrebno tudi posredne ekonomske izgube, kot so izgube bodočega prirastka, stroški obnove, padec cen lesa na trgu in večanje cen delovne sile. 